\title{
Redox-dependent BMI1 activity drives in vivo adult cardiac progenitor cell differentiation
}

\author{
Diego Herrero ${ }^{1} \cdot$ María Tomé $^{2}$ S Susana Cañón ${ }^{1,2} \cdot$ Francisco M. Cruz ${ }^{2}$ Rosa María Carmona ${ }^{1}$ - Encarna Fuster ${ }^{4}$. \\ Enrique Roche ${ }^{3,4} \cdot$ Antonio Bernad ${ }^{1,2}$
}

Received: 18 April 2017 / Revised: 20 October 2017 / Accepted: 23 October 2017 / Published online: 11 January 2018

๑) ADMC Associazione Differenziamento e Morte Cellulare 2018

\begin{abstract}
Accumulation of reactive oxygen species (ROS) is associated with several cardiovascular pathologies and with cell cycle exit by neonanatal cardiomyocytes, a key limiting factor in the regenerative capacity of the adult mammalian heart. The polycomb complex component BMI1 is linked to adult progenitors and is an important partner in DNA repair and redox regulation. We found that high BMI1 expression is associated with an adult Sca1 ${ }^{+}$cardiac progenitor sub-population with low ROS levels. In homeostasis, BMI1 repressed cell fate genes, including a cardiogenic differentiation program. Oxidative damage nonetheless modified BMI1 activity in vivo by derepressing canonical target genes in favor of their antioxidant and anticlastogenic functions. This redox-mediated mechanism is not restricted to damage situations, however, and we report ROS-associated differentiation of cardiac progenitors in steady state. These findings demonstrate how redox status influences the cardiac progenitor response, and identify redox-mediated BMI1 regulation with implications in maintenance of cellular identity in vivo.
\end{abstract}

\section{Introduction}

Several studies have reported that mammals generate new mature cells, including cardiomyocytes, throughout their lifetime, although the contribution of different populations to adult cardiac turnover continues to be debated [1]. At

Edited by D. Aberdam

Electronic supplementary material The online version of this article (https://doi.org/10.1038/s41418-017-0022-2) contains supplementary material, which is available to authorized users.

Antonio Bernad

abernad@cnb.csic.es

1 Department of Immunology and Oncology, Spanish National Center for Biotechnology (CNB-CSIC), Madrid, Spain

2 Cardiovascular Development and Repair Department, Spanish National Cardiovascular Research Center (CNIC), Madrid, Spain

3 CIBERobn (Physiopathology of Obesity and Nutrition CB12/03/ 30038), Carlos III Health Research Institute (ISCIII), Madrid, Spain

4 Department of Applied Biology-Nutrition and Institute of Bioengineering, University Miguel Hernández, Institute for Health and Biomedical Research (ISABIAL-FISABIO Fundation), Alicante, Spain difference from other adult tissues, there is no complete characterization of these "progenitor cells", of which SCA1 is the most widely used membrane marker [2,3]. Despite its widespread use as a cardiac progenitor surface marker, SCA1 cardiac cells are a heterogeneous population that includes adult cardiac progenitor cells [3-5]. Adult progenitors are located in niches that provide a low oxidative environment, which regulates their cell cycle status and metabolism[6]. Several attempts have been made to define the cardiac cells with the lowest reactive oxygen species (ROS) levels, based on expression of the hypoxic marker hypoxia inducible factor-1 alpha before HIF-1 $\alpha$. Recent reports identified rare proliferative HIF- $1 \alpha^{+}$cardiomyocytes [7] and hypoxic cells associated with the epicardium, the least-vascularized heart area [8]. The adult heart nonetheless has the highest oxygen tension of any organ, and adult stem cells are also associated with non-hypoxic adult vasculature $[9,10]$. Hypoxia inducible factor-1 alpha

The relationship between the adult stem cell and ROS has been studied extensively in several adult stem cell populations [11, 12]: but the role of ROS in adult cardiac cell turnover and progenitor behavior is little explored. ROS have important functions in adult tissue homeostasis, and affect both differentiated cells and adult stem cells [13]. Low ROS levels are necessary for adult progenitor cell proliferation, 
and a ROS increase primes progenitor differentiation in several tissues $[12,14]$. The heart is not an exception and its highest regeneration capacity is found during development of the embryo, which resides in a relatively hypoxic environment [15]. These reports suggest a role of oxidative damage in adult cardiac progenitor cell behavior.

BMI1 is a member of the polycomb repressive complex 1 (PRC1), which is linked to multipotent cell populations [16-18]. including those in the heart. [19] BMI1 acts as an epigenetic repressor, remodeling chromatin through histone monoubiquitination [20] Among its main targets, PCR1 represses Hox, p16 $6^{\mathrm{INK} 4 \mathrm{a}}$ and master differentiation genes [21, 22]. Additional PCR1 functions are described in mammalian somatic cells; BMI1 is needed for constitutive heterochromatin formation [23] and is recruited to DNA breaks after DNA damage [24]. thus reducing $\mathrm{G}_{2} / \mathrm{M}$ checkpoint activation [25]. Finally, BMI1 deficiency induces a ROS increase due to mitochondrial dysfunction [26, 27]. This crossroad between cell metabolism and progenitor cell maintenance suggests BMI1 as a pivotal molecule in the regulation of progenitor cell identity.

Here we show that differentiation status is directly related to ROS levels in adult cardiac progenitor cells in homeostasis. Moreover, we found that the contribution of cardiac $\mathrm{Bmil}^{+}$cells to mature cardiac progeny increases after genotoxic stress, and that this response is triggered by an increase in ROS levels. Our results confirm that oxidative stress modifies BMI1 function in vivo, to promote deregulation of canonical target genes, which leads to differentiation. The reduction of pathology-related ROS levels rescued the $\mathrm{BMI}^{-}$related epigenetic function in vivo. This relationship between oxidative stress and progenitor cell differentiation highlights $\mathrm{ROS}$ as a central regulator of in vivo adult cardiac progenitor turnover.

\section{Results}

\section{A postnatal increase in ROS levels induces terminal differentiation of cardiac Bmi1 ${ }^{+}$cells}

An important result of aerobic metabolism is the generation of ROS, which cause postnatal cardiomyocyte exit from the cell cycle in vivo [15] and is linked with differentiation in various adult stem cell systems [28]. To evaluate the effect of an acute increase in ROS levels in cardiac progenitor cells in vivo, we analyzed the differentiation status of Bmi1derived cells between postnatal days 1 and 14. Mammalian fetal heart resides in a relatively hypoxic environment, and in the 2 weeks after birth, there is an acute increase in ROS (Supplementary Figure 1A) and DNA damage. [15] We induced lineage tracing by tamoxifen (Tx) administration in Bmil ${ }^{\mathrm{CreERT} /+} \mathrm{R} 26^{\text {Tomato/+ }}$ mice at embryonic day (E) 18.5.
Hearts were harvested on different postnatal days $(\mathrm{P})$, coinciding with low ROS levels (P1), binucleation and cardiomyocyte cell cycle exit (P7), and young heart with high ROS levels (P14). Cryosections at P1 showed Bmi1-derived cells located extensively throughout atria and ventricles, including ventricular septum and compact myocardium (Fig. 1a). Most of these cells did not express mature cardiac markers (Fig. 1b). At P7 and P14, we detected no Bmi1-derived cell expansion, but mainly age-dependent differentiation, coinciding with the reported increase in cardiac ROS levels; this effect was especially prominent from P1 to P7 (Fig. 1b). We detected no Tomato $^{+}$cells in vehicle-treated Bmil ${ }^{\text {CreERT/ }}$ ${ }^{+} \mathrm{R} 26^{\text {Tomato/+ }}$ mice at P14 (three hearts; 60 longitudinal sections) (Supplementary Figure 1B). These results suggest that the oxygen-rich postnatal environment enforces $\mathrm{Bmil}^{+}$cardiac progenitor differentiation in a ROS-dependent manner.

\section{High BMI1 expression is associated with a cardiac $\mathrm{Sca}^{+}$progenitor sub-population with low ROS levels in adult mice}

To analyze the functional benefits of high Bmil expression in vivo, we used $\mathrm{Bmil}^{\mathrm{GFP} /+}$ transgenic mice [29], in which reporter expression is controlled by the Bmil promoter and allows direct identification of $\mathrm{Bmi1}^{+}$cells. As BMI1 is a master regulator of redox status [30,31], we measured total ROS levels of Bmi1-positive and -negative cardiac cells and cardiomyocytes in homeostasis. As predicted, the $\mathrm{Bmil}^{+}$ cardiac cells had low ROS levels (Fig. 2a), a common characteristic of adult progenitors [6]. We sorted adult Bmi1 ${ }^{+}$cells to analyze the functional benefits of high Bmil expression in vitro. Contrary to our prediction, $<20 \%$ of sorted Bmi $1^{+}$cells maintained Bmil expression after 5 days in culture, and mRNA analysis confirmed acute Bmil downregulation (Fig. 2b). As Bmil expression in the heart is associated mainly with $\mathrm{Sca}^{+}$cardiac progenitors [19], we used a lentiviral BMI1 overexpression system to analyze putative BMI1-associated effects in $\mathrm{Sca}^{+}$cardiac progenitor cells [32]. The cardiac progenitors that overexpress BMI1 (Sca1 ${ }^{\text {Bmil }}$ ) showed greater tolerance to an oxidative environment than controls ( $\mathrm{Sca}{ }^{\mathrm{Ctrl}}$ ), although we found no differences in double-strand break formation or repair after gamma irradiation ( $\gamma$-IR)-induced DNA damage (Fig. 2c). The results suggest that BMI1 expression depends on the heart environment and regulates redox balance in cardiac progenitors in vitro.

\section{Redox status determines the cardiomyocyte lineage commitment of cardiac progenitors in adult mice}

We hypothesized that in vivo cardiac progenitor differentiation in the postnatal window due to acute ROS increase is an amplification of adult cardiac progenitor differentiation 
A

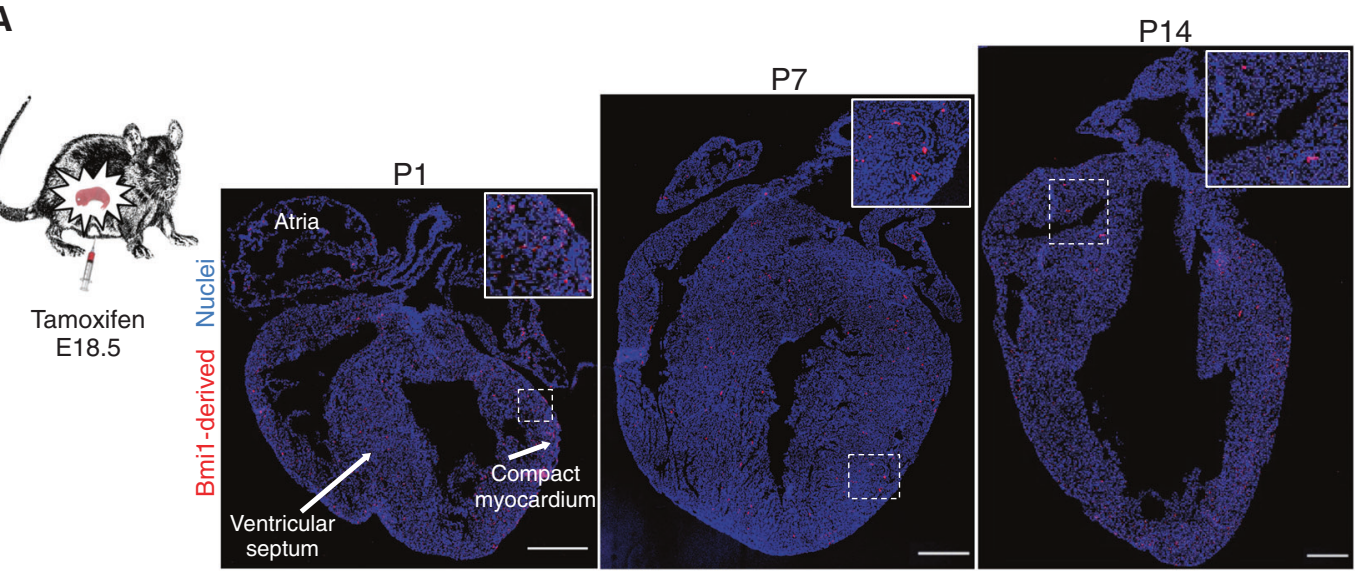

B $\quad \mathrm{P} 1$

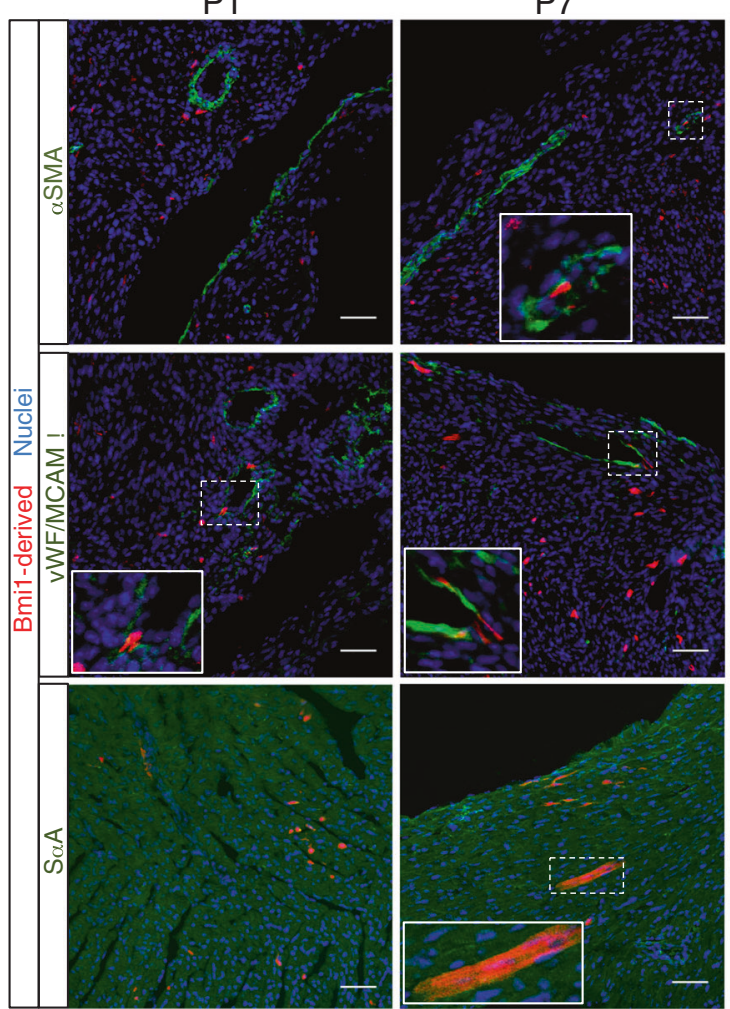

P14
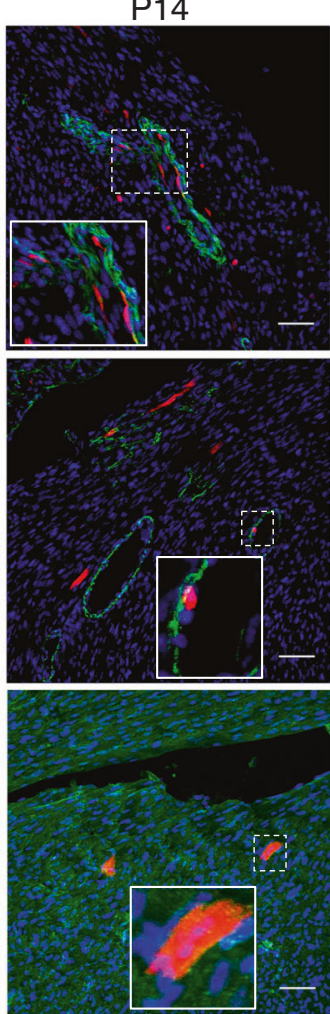

Myofibroblast / smooth muscle

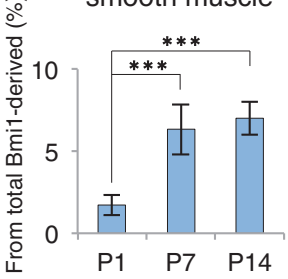

Endothelium
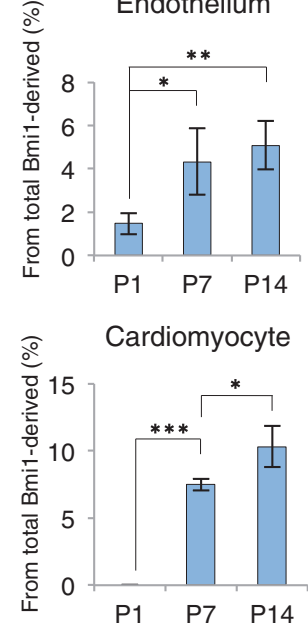

Fig. 1 The oxygen-rich postnatal environment induces cardiac progenitor cell differentiation. a Longitudinal section images of Bmil${ }_{\text {CreERT/+ }}$ R26 ${ }^{\text {Tomato/+ }}$ hearts on distinct postnatal days (P1, P7, and P14). Insets, Bmil-derived cells $(\times 3$ magnification $)$. Bars, $500 \mu \mathrm{m}$. b Representative immunohistochemistry (IHC) images and

in steady state. Nonetheless, analysis of the in vivo physiological effect of ROS on cardiac differentiation is technically difficult due to the low turnover rate in adult heart. We used Myh6 ${ }^{\text {MerCreMer/+ }}$ R26 $6^{\text {Tomato/+ }}$ mice to identify and track recently defined cardiomyocyte-committed progenitor cells in the adult heart (Myh6 ${ }^{+}$non-myocyte cells; cardioblasts) [33]. Analysis of the non-myocyte fraction from Tx- quantification of the percentage of Bmil-derived cells that express mature cardiac surface markers at $\mathrm{P} 1, \mathrm{P} 7$, and $\mathrm{P} 14(n=3)$. Insets, Bmil-derived differentiated cells $(\times 5$ magnification $)$. Bars, $50 \mu \mathrm{m}$. $* p$ $<0.05, * * p<0.005, * * * p<0.001$; one-way ANOVA Tukey's post hoc test. Data shown as mean \pm SEM

induced Myh6 $6^{\text {MerCreMer/+ }} \mathrm{R} 26^{\text {Tomato/+ }}$ mice showed Tomato ${ }^{+}$ cells (cardioblasts), which were not detected in vehicleinduced mice (Fig. 3a). Histology confirmed the presence of $\mathrm{Myh}^{+}{ }^{+} \mathrm{Sca}^{+}$progenitor cells that did not express mature cardiomyocyte S $\alpha$ A (Supplementary Figure 1C). In accordance with the proposed cardiomyocyte-committed state of these cells, we observed a significant reduction in 
Fig. 2 High Bmi1 expression correlates with low ROS levels in adult heart. a In vivo mean fluorescence intensity (MFI) of reactive oxygen species (ROS) levels in cardiac $\mathrm{Bmil}^{+}$cells (green), Bmi1 ${ }^{-}$cells (blue), and cardiomyocytes (purple) from $\mathrm{Bmil}^{\mathrm{GFP} /+}$ mice $(n=4)$. $* * p<$ 0.005; one-way ANOVA

Tukey's post hoc test. b In vitro culture of $\mathrm{Bmil}^{+}$cells from $\mathrm{Bmi1}{ }^{\mathrm{GFP} /+}$ mice induced downregulation of Bmil expression, measured by FACS and RT-qPCR $(n=3)$. ***p $<$ 0.001; unpaired Student's $t$-test. c Relative in vitro proliferation rate in oxidative medium (left) and in vitro DNA damage (53BP1 foci) repair response after $\gamma$-irradiation (IR) (right) between Sca1 ${ }^{\text {Ctrl }}$ (blue) and Sca1 ${ }^{\text {Bmil } 1}$ cells (red) $(n=3) . * p$ $<0.05$, $* * p<0.005$; unpaired Student's $t$-test. Data shown as mean \pm SEM
A
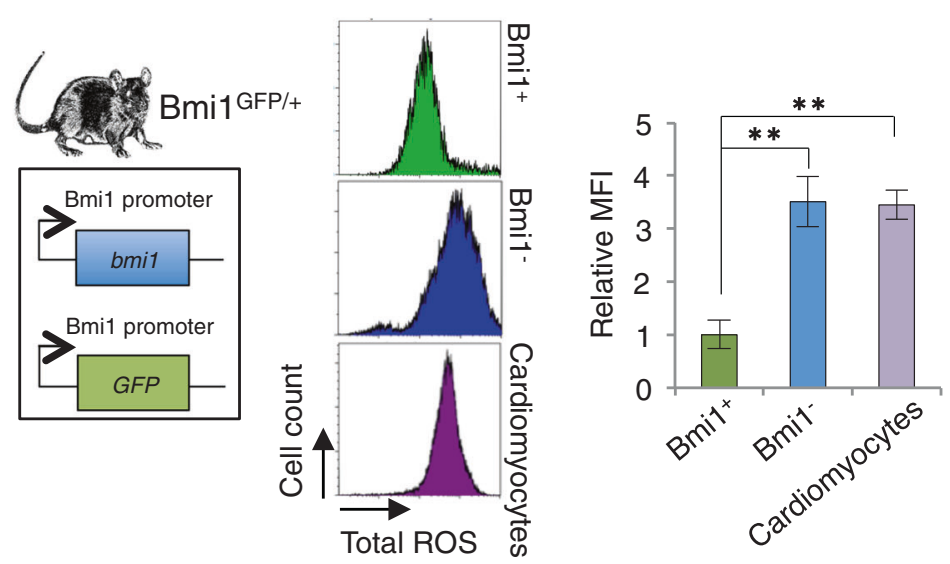

B
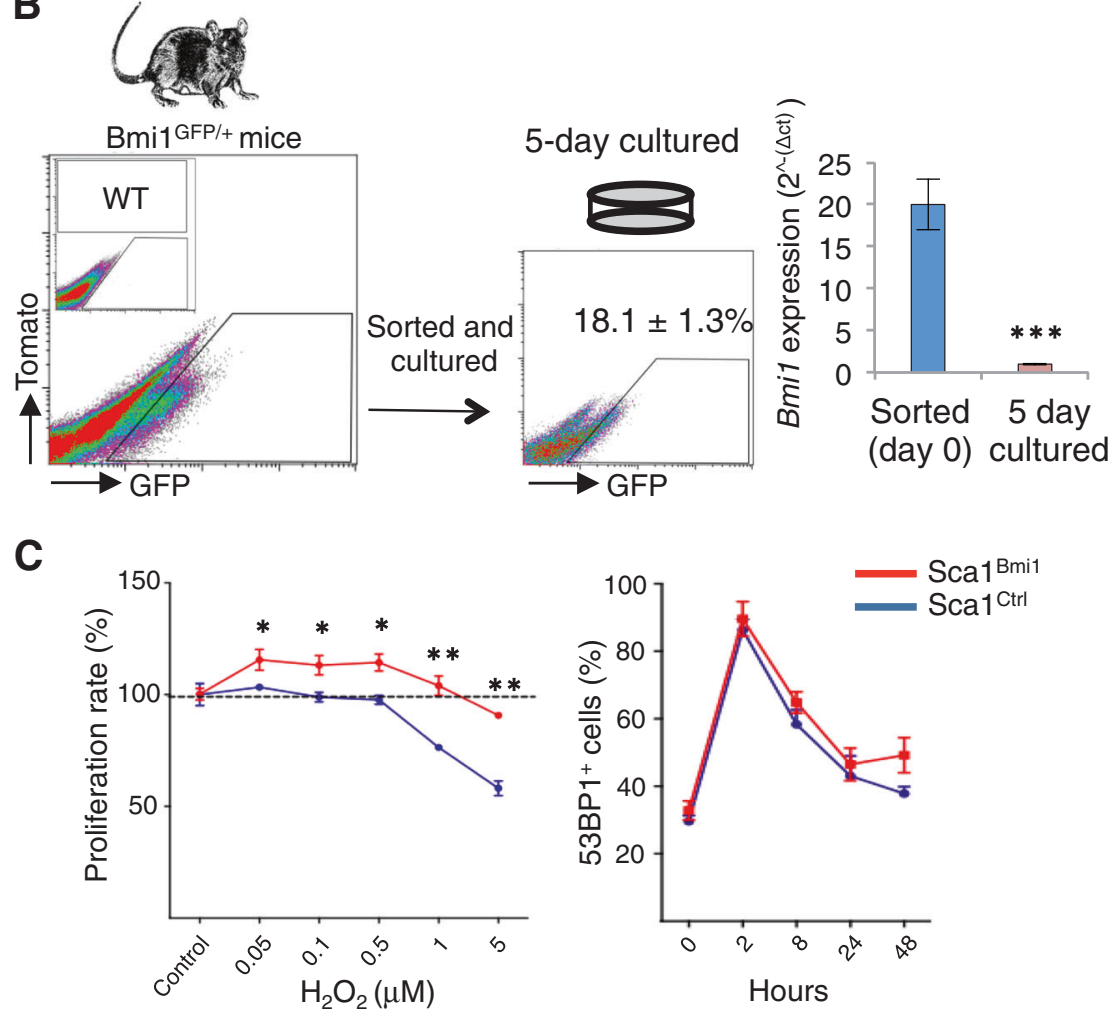

cardioblasts at two months post-Tx induction (Supplementary Figure 1D).

We evaluated whether oxidative stress lead to an increase in cardiomyocyte-committed progenitor cells. We administered Tx to induce Myh6 ${ }^{\mathrm{MerCreMer} /+} \mathrm{R} 26^{\text {Tomato/+ }}$ mice 2 days after paraquat (PQ) treatment, which generates oxidative damage mainly by forming superoxide radicals [34], and found a significant increase in cardioblasts compared with $\mathrm{Tx}$ induction before oxidative damage (Fig. 3b). Data show that oxidative damage causes a clear increase in cardiomyocytecommitted progenitor cells in adult mouse heart.

We examined the relationship between Bmil and mature cardiomyocyte genes. In Bmi1 ${ }^{\mathrm{GFP} /+}$ mice, $\mathrm{Bmi}^{+}$cells with lower Bmil levels $\left(\mathrm{Bmil}^{\text {low }}\right)$ expressed higher levels of cardiogenic genes (Myh6 and Tnnt2) than Bmi ${ }^{+}$cells with higher Bmil levels (Bmil ${ }^{\text {high }}$ ) (Supplementary Figure 1E). These results suggest an inverse relationship between expression of Bmil and cardiogenic genes. To test the overlap between $\mathrm{Myh}^{+}$and $\mathrm{Bmil}^{+}$adult cardiac populations, we generated a triple transgenic $\mathrm{Myh}^{\mathrm{MerCreMer} /}$ ${ }^{+} \mathrm{R} 26^{\text {Tomato/+ }}{ }^{\mathrm{Bmi1}}{ }^{\mathrm{GFP} /+}$ mouse line. In these mice, $\mathrm{Bmi1}{ }^{+}$ progenitor cells were $\mathrm{GFP}^{+}$; after Tx induction, $\mathrm{Myh6}^{+}$ cells were irreversibly Tomato labeled, and $\mathrm{Bmil}^{+} \mathrm{Myh}^{+}$ cells were double-positive (GFP and Tomato). Analysis of adult hearts 5 days post-Tx induction showed that $0.75 \%$ of non-myocyte cells were double-positive $\left(\mathrm{Myh}^{+} \mathrm{Bmil}^{+}\right)$, 
A

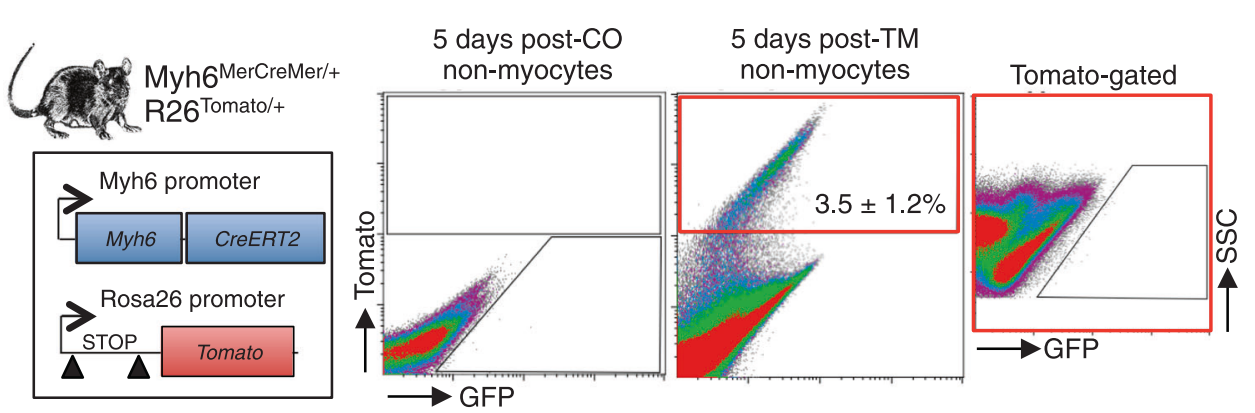

B
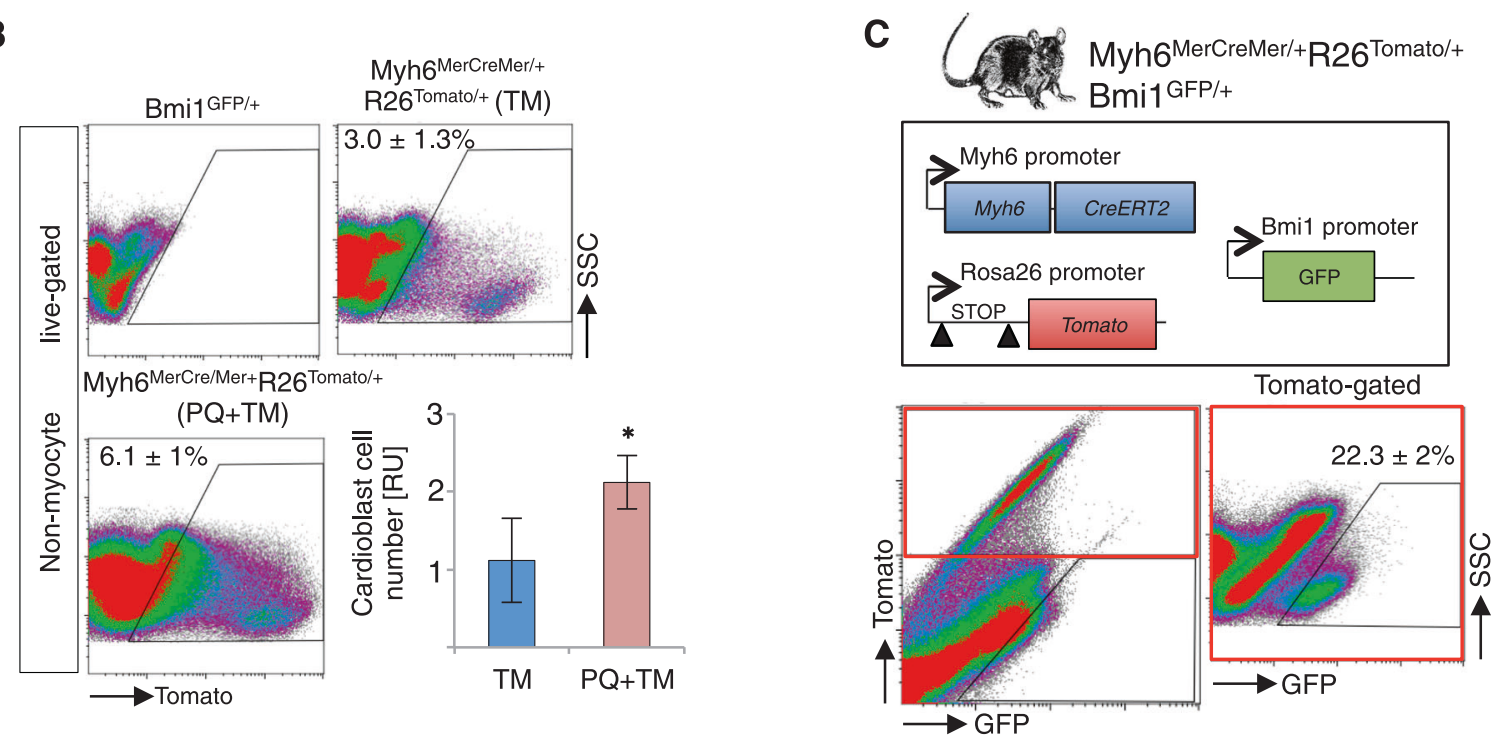

D

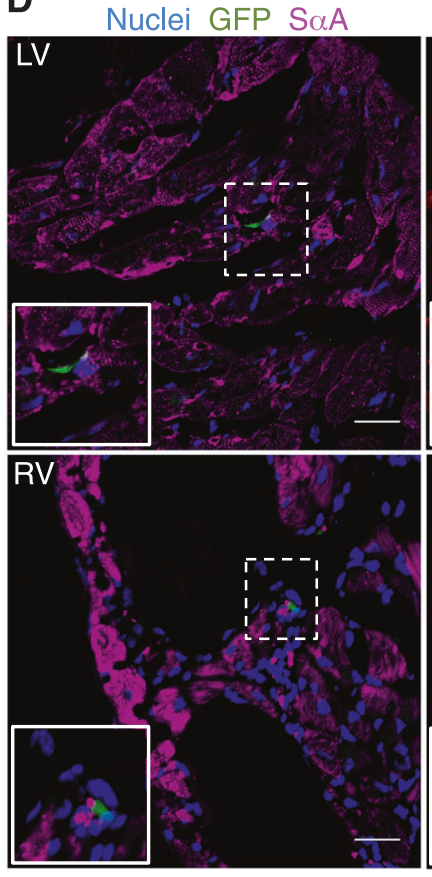

Nuclei GFP Tomato

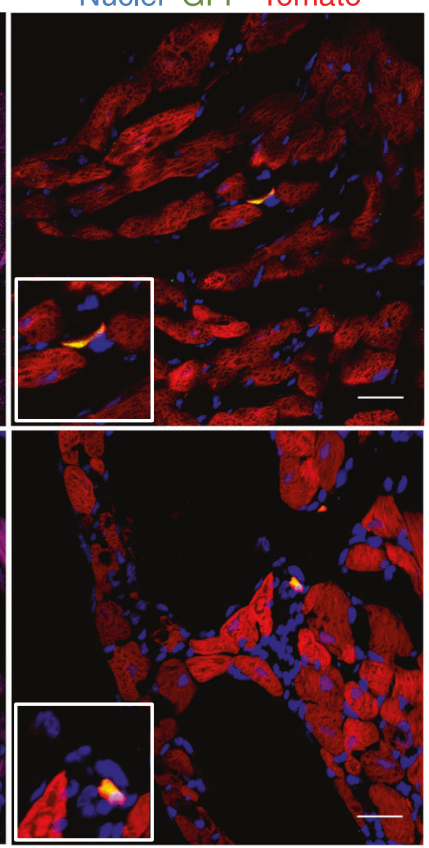

$\mathbf{E}$

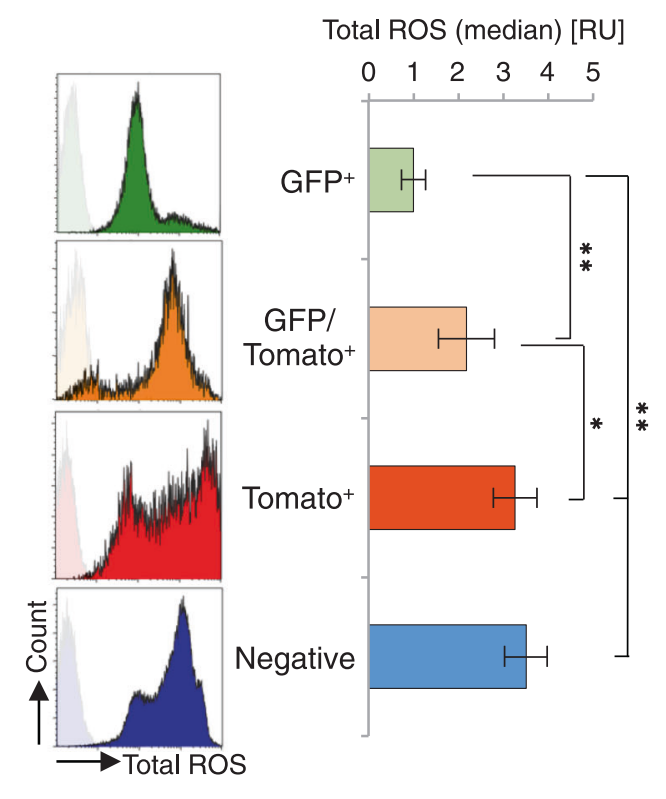

approximately $25 \%$ of the cardioblasts $\left(\mathrm{Myh}^{+}\right)$were $\mathrm{Bmil}$ positive (Fig. 3c). Histology confirmed that these cells were mononucleated and S $\alpha \mathrm{A}$ negative (Fig. 3d and
Supplementary Figure 1F). Phenotypic characterization of these populations by fluorescent-activated cell sorting (FACS) showed that they are virtually c-KIT-negative 
Fig. 3 ROS levels correlate with in vivo adult $\mathrm{Bmi}^{+}$cardiac progenitor cell differentiation status. a Representative FACS plot of non-myocyte cells at 5 days after corn oil (post-CO) and Tx induction (post-TM) in Myh6 ${ }^{\mathrm{Cre} /+} \mathrm{R} 26^{\mathrm{Tomato} /+}$ mice $(n=4)$. b Representative FACS plots and quantification of cardiac $\mathrm{Myh}^{+}$cells $\left(\right.$Tomato $^{+}$) in heart in homeostasis (blue bar) and after oxidative stress (PQ) (red bar). Myh6 ${ }^{\mathrm{Cre} /+}$ Rosa $26^{\text {Tomato/+ }}$ mice were analyzed five days after Tx treatment (TM) $(n=4) .{ }^{*} p<0.05$; unpaired Student's $t$-test. c Representative FACS plot at five days post-Tx induction in $\mathrm{Myh} 6^{\mathrm{MerCreMer} /+} \mathrm{R} 26^{\text {Tomato/ }}$ ${ }^{+} \mathrm{Bmil}^{\mathrm{GFP} /+}$ mouse heart, showing $\mathrm{GFP}^{+}(4.5 \%)$, Tomato ${ }^{+}(3 \%)$, and double-positive $(0.75 \%)$ cells $(n=4)$. Double-positive cells are $22.3 \pm$ $2 \%$ of the $\mathrm{Myh}^{+}$cell population. Representative FACS controls of vehicle-induced (negative) and Tx-induced (Tomato ${ }^{+}$) Myh6 ${ }^{\text {MerCreMer/ }}$ ${ }^{+}$Rosa $26^{\text {Tomato/+ }}$ mice are shown in panel a. d IHC on cryosections confirmed the presence of double-positive non-myocyte cells at 5 days post-Tx induction in $\mathrm{Myh} 6^{\mathrm{MerCreMer} /+} \mathrm{R} 26^{\mathrm{Tomato} /+} \mathrm{Bmi} 1^{\mathrm{GFP} /+}$ mice. Insets, double-positive cells $\left(\mathrm{GFP}^{+}\right.$Tomato $\left.^{+}\right)(\times 5$ magnification $)$. Bars, $50 \mu \mathrm{m}$. e FACS quantification of total ROS levels in nonmyocyte fraction at 5 days post-Tx induction in Myh6 $6^{\text {MerCreMer/ }}$ ${ }^{+} \mathrm{R} 26^{\text {Tomato/+ }} \mathrm{Bmi1}{ }^{\mathrm{GFP} /+}$ mice. Top: histograms of total ROS levels of indicated cardiac populations. Bottom: quantification (median fluorescence intensity) of total ROS levels for these cell populations $(n=$ 4). Left ventricle (LV), right ventricle (RV), relative units (RU). ${ }^{*} p<$ $0.05, * * p<0.005$; one-way ANOVA Tukey's post hoc test. Data shown as mean \pm SEM

(Supplementary Figure 2). Bmi1 ${ }^{+}$cells express SCA1 more frequently than $\mathrm{Myh}^{+}$or $\mathrm{Bmil}^{+} \mathrm{Myh}^{+}$cells; all three populations have cells positive for PDGFR $\alpha$ - and CD31related progenitor markers, although in different proportions (Supplementary Figure 2). The data suggest overall that BMI1 and MYH6 do not define a homogeneous cardiac progenitor cell population, and we cannot rule out the presence of several types of adult progenitors within these populations or a correlation between BMI1 levels and a specific metabolic state of the cells. fluorescent-activated cell sorting (FACS) platelet-derived growth factor receptor $\alpha(\mathrm{PDGFR} \alpha)$

To compare BMI1 expression and committed status, we quantified total ROS levels in Myh6 ${ }^{\text {MerCreMer/+ }}$ R26 ${ }^{\text {Tomato/+ }}$ Bmil ${ }^{\mathrm{GFP} /+}$ mice. Flow cytometry analysis showed that $\mathrm{Bmil}^{+} \mathrm{Myh6}^{-}$cells had the lowest and Bmi1 ${ }^{-} \mathrm{Myh6}^{+}$cells the highest total ROS levels, whereas double-positive cells had an intermediate ROS level (Fig. 3e). These data strongly suggest that cardiac $\mathrm{Bmil}^{+}$cells are the origin of at least part of adult cardiomyocyte-committed cells, and indicate a direct relationship between ROS levels and the cardiomyocyte-committed status of cardiac progenitors in the adult mouse.

\section{Genotoxic damage increases cardiac progenitor differentiation rate in adult mice}

Various pharmacological drugs are linked to ROS increase in mice, but there is no treatment that induces ROS increase without DNA damage [12, 15]. To link ROS increase with adult cardiac progenitor differentiation, we tested several types of genotoxic damage. We gamma-irradiated $(\gamma$-IR; 9
Gy) adult heart after $\mathrm{Tx}$ administration in Bmi1 ${ }^{\mathrm{CreERT} /+}$ $\mathrm{R} 26^{\mathrm{YFP} /+}$ mice [16] to examine the relative contribution of cardiac $\mathrm{Bmil}^{+}$cells and of their progeny to mature heart populations. Genotoxic damage rapidly increased total and mitochondrial ROS levels (Supplementary Figures 3A and 3B). Four months after $\gamma$-IR, immunohistochemistry (IHC) analyses showed a significant increase in the $\mathrm{Bmil}^{+}$cell contribution to endothelial (2.5-fold), smooth muscle (3.9fold), and cardiomyocyte lineages (2.8-fold) compared with unirradiated mice (Supplementary Figure 3C). The multifactorial nature of $\gamma$-IR-derived damage prompted us to test other, more specific genotoxic reagents. For preferential evaluation of oxidative stress, we used PQ dichloride, and of DNA damage, we used the anticancer drug mitomycin-C (MMC), which induces DNA crosslinks that block DNA replication and transcription (Supplementary Figure 4A) [35]. At 4 months after damage, we evaluated $\mathrm{Bmi1}^{+}$cell differentiation to cardiomyocytes in $\mathrm{Bmi} 1^{\mathrm{CreERT} /}{ }_{\mathrm{R}} 26^{\mathrm{YFP} /+}$ mice to assess the genotoxic differentiation effect. We used immunocytochemistry (ICC) to quantify results in freshly plated cardiomyocytes and FACS for confirmation, with a cardiomyocyte-specific gating strategy based on size difference between non-myocyte cells and cardiomyocytes (Supplementary Figure 4B) [19, 36]. Genotoxic reagents similarly induced an increase in Bmil-derived cardiomyocytes compared with control hearts (Supplementary Figures 4C and 4D and Supplementary Table 1). Results suggest that ROS are the main effectors in $\mathrm{Bmil}^{+}$cell differentiation after oxidative damage.

To confirm this hypothesis, we tested whether ROS scavenging with the antioxidant $\mathrm{N}$-acetylcysteine (NAC) rescued oxidative damage (Supplementary Figure 4A). A decrease in total ROS levels (Supplementary Figure 4E) was accompanied by a significant reduction in Bmilderived cardiomyocytes at the end of treatment (4 months) (Supplementary Figures 4C and 4D), although antioxidant treatment was unable to prevent ROS-related differentiation completely. rescued oxidative damage (Supplementary Figure 4A)

\section{BMI1 regulates cardiac progenitor differentiation through its antioxidant- and anticlastogenic-related functions}

BMI1 was originally described as an epigenetic repressor through monoubiquitination of histone 2A (H2AK119ub) [37]. Several groups have also reported various roles for BMI1 in redox maintenance and DNA damage repair [25, 26, 38-40]. We thus hypothesized that oxidative stress derepresses BMI1 canonical DNA targets in favor of stressrelated functions.

Oxidative damage in primary cardiac $\mathrm{Bmi1}^{+}$cells in vitro $\left(1 \mu \mathrm{M} \mathrm{H} \mathrm{H}_{2} \mathrm{O}_{2}\right)$ induced downregulation of stemness- 


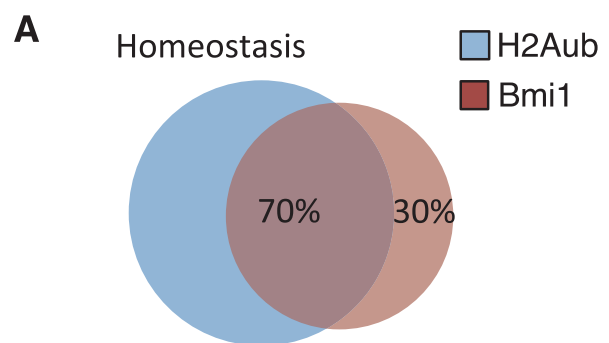

Oxidative damage (PQ)

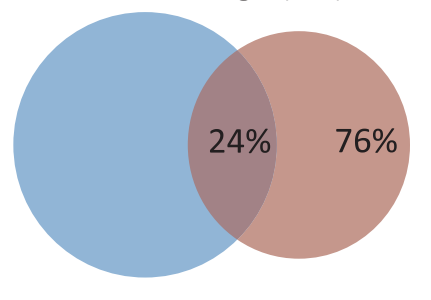

C

D
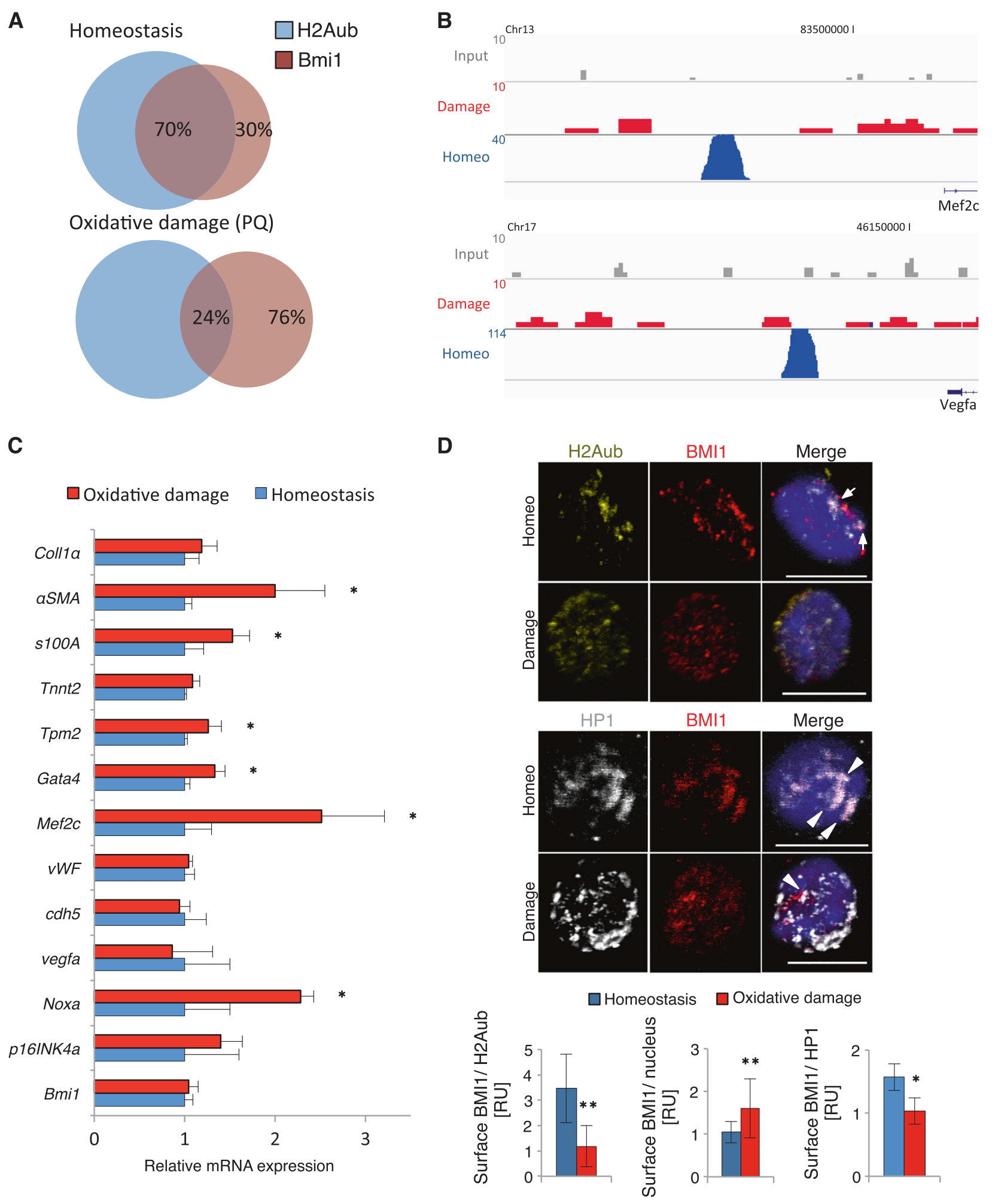

related genes and upregulation of differentiation-related genes, with no marked changes in Bmil levels (Supplementary Figure 5A). To determine the in vivo effects of oxidative stress, we performed chromatin immunoprecipitation (ChIP) (against BMI1 and H2AK119ub), followed by massive parallel DNA sequencing (ChIP-seq) of Sca1 ${ }^{+} \mathrm{CD} 45^{-}$cardiac progenitors at 10 days post-PQ treatment. We found no differences in cardiac BMI1 expression or $\mathrm{Bmil}^{+}$cell number shortly after oxidative damage (Supplementary Figures 5B and 5C). Ingenuity pathway analysis 
Fig. 4 Oxidative damage induces derepression of BMI1 canonical target genes and promotes differentiation. a Venn diagrams summarize the percentage of coexpression of peaks called from BMI1 and $\mathrm{H} 2 \mathrm{Aub}-\mathrm{seq}$ in homeostasis and after oxidative damage (PQ). b Integrative Genomics Viewer views of binding profiles for differentiationrelated genes of cardiac progenitor cells $\left(\mathrm{Scal}^{+} \mathrm{CD} 45^{-}\right)$from control mice (homeostasis) and PQ-treated mice (damage). Chr, chromosome. c In vivo differentiation-related gene expression in Bmi1-derived cells from $\mathrm{Bmi} 1^{\mathrm{CreERT} /+} \mathrm{R} 26^{\mathrm{YFP} /+}$ mice 10 days post-PQ treatment (red) and age-matched control Bmi1-derived cells (homeostasis; blue) by RTqPCR $(n=3)$. d Nuclear location of H2Aub (yellow), BMI1 (red) and $\mathrm{HP} 1$ (gray) in Bmil-derived cells from Bmi1 ${ }^{\mathrm{CreERT} /+} \mathrm{R} 26^{\mathrm{YFP} /+}$ mice 10 days post-PQ treatment (damage) compared with age-matched control mice (homeo). Top: representative immunocytochemistry (ICC) images of nuclear coexpression of BMI1/H2Aub (arrows) and BMI1/HP1 (arrowheads) in homeostasis and after PQ treatment. Bars, $10 \mu \mathrm{m}$. Bottom: quantification of the coexpression in homeostasis (blue) and after PQ treatment (red) $(n=3 ; \geq 40$ cells per mouse). Statistical analyses: ${ }^{*} p<0.05,{ }^{*} p<0.005$; unpaired Student's $t$-test. Data shown as mean \pm SEM

of BMI1- and H2AK119ub-related peaks in homeostasis revealed an enrichment in differentiation-related genes ( $v W F, C d h 5, T p m 2$, Tnntl, and Mef2c) and BMI1 peaks, also in stemness-related genes (Atg5, Atg7, and Hoxb1) (Supplementary Table 2). After oxidative damage, we detected an unanticipated sharp decrease in the number of peaks ( $>90 \%$ ) compared with homeostasis conditions, with very few specific peaks called from BMI1 and H2AK119ub ChIP-seq. In addition, only $25 \%$ of BMI1 peaks overlapped with H2AK119ub peaks after PQ treatment, compared with $>70 \%$ in steady state (Fig. 4a). The peaks absent after damage included some genes related to endothelial, fibroblast, and cardiomyocyte differentiation genes, and several signaling pathways were predicted to be affected (Fig. 4b, Supplementary Figure 5D and Supplementary Table 2). In Bmil-derived cells from Bmi1 ${ }^{\mathrm{CreER} /+} \mathrm{R} 26^{\mathrm{YFP} /+}$ PQ-treated mice, we found upregulation of several differentiationrelated genes, particularly of cardiomyocyte- and myofibroblast-related genes (Fig. 4c), which confirmed ChIP-seq data. These results suggest that in vivo oxidative stress induces an acute loss of BMI1 canonical DNA target peaks, which promotes expression of differentiation-related genes.

In mammals, BMI1 accumulates as discrete nuclear foci and is linked with transcriptional silencing and heterochromatin proteins [20,23]. We used ICC to analyze the nuclear BMI1 distribution after 10 days of PQ treatment in Bmil-derived cells from Bmi ${ }^{\text {CreERT/+}} \mathrm{R} 26^{\mathrm{YFP} /+}$ mice. The number of BMI1/H2AK119ub-coexpressing foci decreased after oxidative stress (Fig. 4d, top), which again supported ChIP-seq results. We also detected a significant increase in the area of BMI1 nuclear staining, but less coexpression with HP1, one of the major heterochromatin proteins, as well as dynamic relocalization after oxidative stress
(Fig. $4 \mathrm{~d}$, bottom). With the previous data, these results strongly suggest that oxidative damage induces BMI1 delocalization from canonical DNA targets linked to upregulation of differentiation-related genes.

\section{ROS-related BMI1 function induces its delocalization from DNA canonical targets in vivo}

We used the Bmil heterozygous knockout mice $\left(\mathrm{Bmi}^{+/ \mathrm{GFP}} ; \mathrm{Bmi}^{+/-}\right.$) to further confirm ROS involvement in BMI1 function in in vivo homeostasis. These transgenic mice are characterized by an early aging-like phenotype, due in part to increased oxidative damage [41, 42]. To decrease the oxidative damage without affecting Bmil alleles, we crossed $\mathrm{Bmi1}^{+/-}$mice with glucose-6-phosphate dehydrogenase (G6PD) transgenic mice. These mice show a reduction of oxidative stress in several organs, including heart [43].

We assessed the epigenetic signature by (ChIP-qPCR) on several canonical BMI1 DNA targets in $\mathrm{Sca} 1^{+} \mathrm{CD} 45^{-}$ cardiac progenitor cells based on our ChIP-seq Bmi1-related targets in homeostasis (Supplementary Table S2) and others previously described [21, 44]. Chromatin silencing was examined by measuring H2AK119ub, and by Bmi1specific binding using hearts under oxidative stress (Bmi1 ${ }^{+/-}$) and with reverted phenotype $\left(\mathrm{Bmil}^{+/-} \mathrm{G}^{\mathrm{PPD}}{ }^{\mathrm{tg}}\right.$ ) (Supplementary Figure 5E). The reduction in oxidative stress led to a significant increase in H2AK119ub and BMI1 signals in Bmil canonical target genes in $\mathrm{Sca}^{+} \mathrm{CD} 45^{-}$cardiac progenitor cells in $\mathrm{Bmil}^{+/-} \mathrm{G} \mathrm{PD}^{\mathrm{tg}}$ compared with $\mathrm{Bmil}^{+/-}$ hearts (Fig. 5a). The increase in BMI1-related epigenetic signals was accompanied by decreased mRNA expression of differentiation-related genes in freshly sorted $\mathrm{Sca}^{+} \mathrm{Bmi} 1$ ${ }^{+}$progenitor cells from $\mathrm{Bmil}^{+/-} \mathrm{G6PD}^{\mathrm{tg}}$ mice (Fig. 5b). These data strongly indicate a ROS-dependent BMI1 function in cell fate decisions in adult cardiac progenitor cells (Fig. 5c).

\section{Discussion}

Cell metabolism is becoming recognized as a determining factor for cell fate and cell cycle status in different organs, including the heart [45]. During heart development, cardiac cells are in a relatively hypoxic environment with anaerobic metabolism and low ROS levels, where proliferation of immature cardiomyocytes is the main regenerative mechanism [46]. Postnatal normoxia increases ROS levels and oxidative damage, inducing cell cycle exit and terminal cardiomyocyte differentiation [15]. The role of ROS in adult cardiac cell turnover and progenitor behavior is nonetheless one of the least-explored sources of information on cardiac regeneration. 

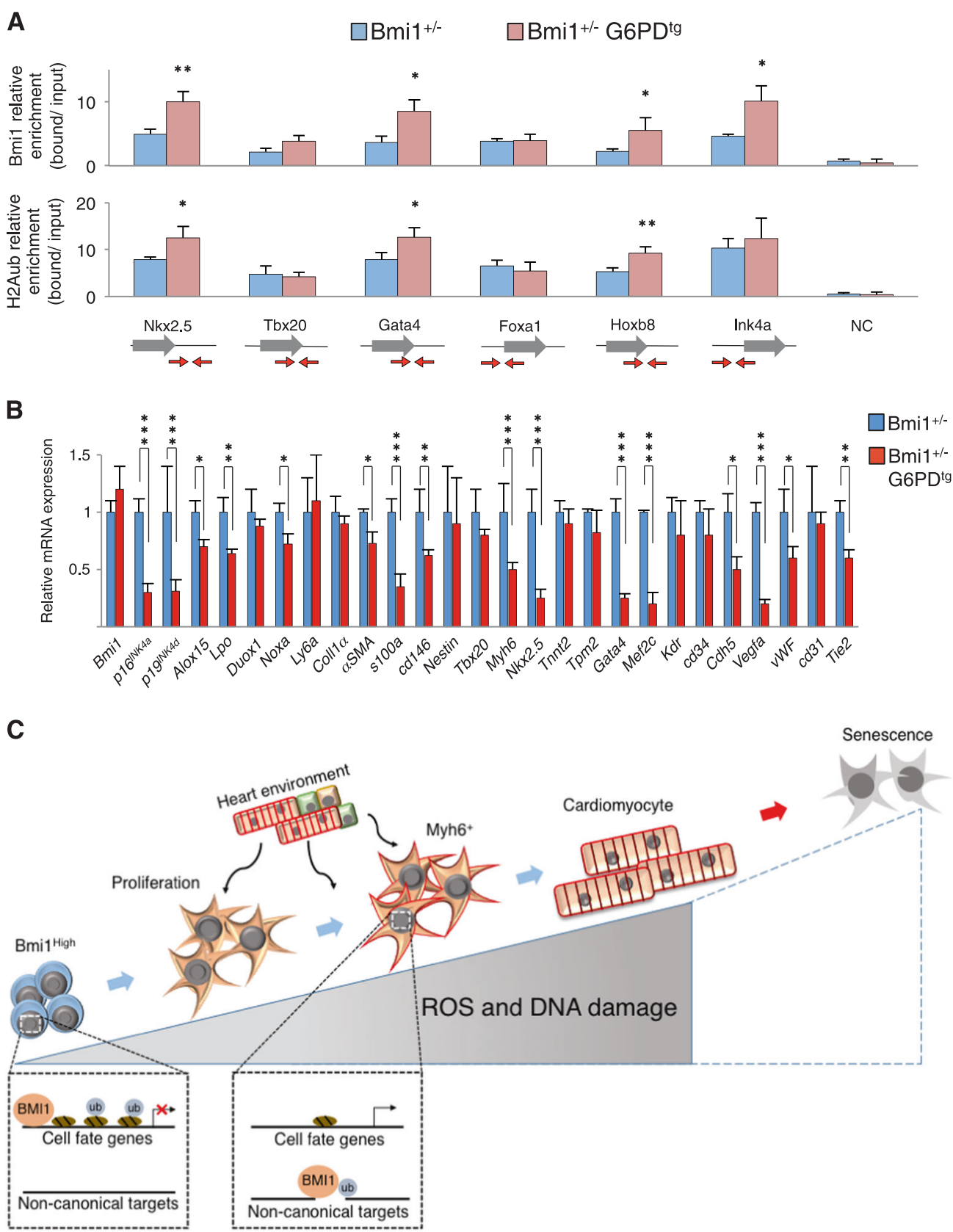

Fig. 5 ROS decrease prevents BMI1 derepression of DNA canonical target genes in vivo. a ChIP-qPCR for BMI1 and K119 ubiquitination of $\mathrm{H} 2 \mathrm{~A}(\mathrm{H} 2 \mathrm{Aub})$ at indicated gene loci in $\mathrm{Scal}^{+}$cardiac progenitor cells from adult $\mathrm{Bmil}^{+/-}$(blue) and $\mathrm{Bmil}^{+/}{ }^{-} \mathrm{G} \mathrm{PD}^{\mathrm{tg}}$ (red) mice $(n=$ 3). Red arrows indicate primer amplification site on the gene. NC (unrelated genomic locus). b In vivo differentiation-related gene expression in $\mathrm{Sca}^{+}{ }^{+}$cardiac progenitor cells from adult Bmi1 ${ }^{+/-}$(blue)

Our data show that one of the critical regulators of adult cardiac progenitor cell differentiation is the level of ROS, which act in part through epigenetic modifications related to the polycomb repressive complex component BMI1. Here we identified an inverse relationship between BMI1 expression and cardiomyocyte differentiation status, and showed that cardiac $\mathrm{Bmil}^{+}$cells make up $25 \%$ of the and $\mathrm{Bmil}^{+/-} \mathrm{G}^{\mathrm{PPD}}{ }^{\mathrm{tg}}$ (red) mice, measured by RT-qPCR $(n=3)$. c Working model. BMI1 regulates cell fate decisions in homeostasis. The increases in ROS and oxidative DNA damage induce an imbalance in BMI1 function; BMI1 is recruited far from canonical cell faterelated DNA targets, which promotes $\mathrm{Bmil}^{+}$cell differentiation. Statistical analyses: $* p<0.05, * * p<0.005,{ }^{* * *} p<0.001$; unpaired Student's $t$-test. Data shown as mean \pm SEM

cardiomyocyte-committed cells $\left(\mathrm{Myh}^{+}\right.$cells) in adult heart. These cardiomyocyte-committed progenitors (Myh6 ${ }^{+} \mathrm{Bmi1}^{+}$) had the highest ROS levels of all adult cardiac progenitor cells. In vitro studies of embryonic stem cell differentiation to cardiomyocytes suggest a relationship between ROS levels and cardiogenic gene expression [47, 48]. here we demonstrate that ROS levels are directly linked 
with myofibroblast- and cardiomyocyte-related gene expression in vivo. In addition, we found that several types of genotoxic damage increased the contribution of Bmilderived progenitors to mature cardiac progeny, and that this ROS-mediated differentiation effect was partially rescued by antioxidant treatment. Although ROS scavenging significantly reduced ROS-related differentiation, it was not entirely avoidable as ROS effects are modulated by its intensity, duration and cell site of action [14, 49, 50].

Several authors have linked ROS with a decrease in autophagy [51] and activation of differentiation-related signaling pathways [52, 53]. We nonetheless focused on upstream events that could regulate these pathways. Two recent reports suggest a PCR1 (BMI1-related polycomb repressive complex) function in epidermal and embryonic stem cell differentiation $[54,55]$. Our results provide in vivo evidence of the effect of cell redox status on BMI1 activity in cardiac progenitor cells. A low oxidative environment allows BMI1 cell fate repressor activity, where BMI1 binds to differentiation-related sites in the DNA. BMI1 function as an epigenetic repressor of differentiation-related genes has been described in other cell types [18, 37, 56]. We observed that in homeostasis conditions, BMI1 represses a cardiogenic differentiation program in $\mathrm{Sca}^{+}$cardiac progenitors in vivo, which emphasize its stemness-related role in adult heart. An acute increase in oxidative damage altered in vivo BMI1 activity by recruiting BMI1 away from canonical DNA targets. This increase did not induce BMI1 upregulation in vitro or in vivo, but triggered an imbalance toward stress-related functions and thus derepressed canonical target genes that regulate cell identity and cell fate decisions. These stress-related functions might include BMI1-related antioxidative and anticlastogenic functions, as reported for several cell types [24, 26, 27, 40]. Similar to a ROS-dependent epigenetic mechanism proposed for Drosophila [57]. we identify BMI1 regulation mediated by cell redox status in mammals.

This ROS-mediated mechanism is not restricted to stressrelated situations such as an acute genotoxic damage or postnatal normoxia, but has a major role in the physiological turnover of adult progenitor cells. Our results show that the reduction of ROS levels in adult heart by G6PD overexpression increased BMI1 binding to canonical DNA targets in cardiac progenitors in vivo. mRNA analysis confirmed the repressor role of the Bmil-derived epigenetic signature in these genes.

Our studies thus demonstrate that ROS levels are a key factor in the switch between the stemness and cell fate of cardiac progenitor cells, in part by derepressing canonical BMI1 target genes related to cell fate decisions. It is tempting to speculate that manipulation of ROS-related pathways and/or stimulation of putative cardiac $\mathrm{Bmil}^{+}$cell-related niches would enhance a hitherto limited regenerative process.

\section{Materials and methods}

\section{Transgenic mice and Tx administration}

Transgenic mice included Myh6 $6^{\text {MerCreMer/+ }}$ [33], Bmil ${ }^{\mathrm{CrERT} /+} \quad$ [16], Bmil ${ }^{\mathrm{GFP} /+}$ [29], Rosa $26^{\mathrm{YFP} /+}$, Rosa $26^{\text {Tomato/+ }}$ (Ai9 Jackson Laboratory), and G6PD ${ }^{\text {tg }}$ mice [43], all on the C57BL/6 background. Tx was dissolved in corn oil (Sigma) and mice received Tx (i.p.) every $24 \mathrm{~h}$ on 3 consecutive days ( $9 \mathrm{mg} / 40 \mathrm{~g}$ body weight). To maximize labeling, Tx was administered to Myh6 ${ }^{\text {MerCreMer/+ }}$ R26 $6^{\text {Tomato/+ }}$ and Myh6 ${ }^{\text {MerCreMer/+ }}$ R26 ${ }^{\text {Tomato/+ }} \mathrm{Bmi} 1{ }^{\mathrm{GFP} /+}$ mice on 5 consecutive days. A $2 \mathrm{mg}$ single oral $\mathrm{Tx}$ dose at 18.5 days post-coitus was used for Cre recombination during development. We included a half-dose of progesterone to reduce abortion rates after Tx treatment. Animal studies were approved by the CNB-CSIC ethics committee and by the Division of Animal Protection of the Comunidad de Madrid (PA 56/11, PROEX 048/16). All animal procedures conformed to EU Directive 2010/63EU and Recommendation 2007/526/EC regarding the protection of animals used for experimental and other scientific purposes, enforced in Spanish law under Real Decreto 1201/2005.

\section{Genotoxic stress damages}

Whole-body $\gamma$-IR was performed in a Cesium Mark1 irradiator (Shepherd Associates). Except where indicated, mice (6-8 weeks old) were irradiated 7 days after Tx treatment, on 2 consecutive days $(4.5 \mathrm{~Gy}+24 \mathrm{~h}+$ $4.5 \mathrm{~Gy}$ ) to minimize high turnover rate tissue damage. To avoid bone marrow aplasia, irradiated mice were transplanted (i.v.) with $10^{6}$ whole $\mathrm{BM}$ cells isolated from age-matched C57BL/6 mice. For oxidative stress experiments, each mouse received a single dose of $20 \mathrm{mg} /$ kg PQ (Sigma) (i.p.) 7 days after Tx treatment. For DNA damage experiments, mice received seven consecutive doses of $1 \mathrm{mg} / \mathrm{kg}$ MMC (Sigma) (i.p.) 7 days after Tx treatment. $N$-acetylcysteine (Sigma) was dissolved in phosphate-buffered saline (PBS) and each mouse received a single dose i.p. of $150 \mathrm{mg} / \mathrm{kg}$, with $1 \mathrm{mg} / \mathrm{ml}$ in drinking water (ad libitum) for 4 months. The NAC dose is comparable to others used to decrease oxidative damage in adult mice [14, 58].

\section{Histology and IHC analyses}

For IHC, hearts were fixed in $4 \%$ paraformaldehyde (PFA; overnight $\left.(\mathrm{O} / \mathrm{N}), 4^{\circ} \mathrm{C}\right)$ and cryopreserved in $30 \%$ saccharose, frozen in optimum cutting temperature, and sectioned in $8-\mu \mathrm{m}$ sections on a cryostat. Heart IHC and ICC have been described in detail [19]. optimum cutting temperature OCT compound 
For ICC detection of nuclear antigen, cells were plated by cytospin $(400 \times g, 4 \mathrm{~min})$, fixed with $4 \%$ PFA (15 min, room temperature (RT)), permeabilized in $0.5 \%$ Triton-X 100 ( $2 \mathrm{~min}, \mathrm{RT}$ ), and blocked in $5 \%$ bovine serum albumin (BSA)/PBS $\left(\mathrm{O} / \mathrm{N}, 4^{\circ} \mathrm{C}\right)$. Slides were then incubated in $1 \%$ $\mathrm{BSA} / \mathrm{PBS}$ with primary antibodies $\left(1-2 \mathrm{~h}, 37^{\circ} \mathrm{C}\right.$ ) (Supplementary Table S3). Slides were washed three times and then incubated in $\mathrm{PBS} / 1 \% \mathrm{BSA}$ with appropriate secondary antibodies $\left(1 \mathrm{~h}, 37^{\circ} \mathrm{C}\right)$. Nuclei were labeled with 4,6-diamidino-2-phenylindole (DAPI; $15 \mathrm{~min}, \mathrm{RT}$ ) and slices were mounted with ProLong antifade reagent (Invitrogen).

For ROS detection, hearts were frozen immediately in OCT, and cryostat sectioned in $8-\mu \mathrm{m}$ sections, stained with dihydroethidium ( $10 \mu \mathrm{M}$ in $\left.\mathrm{PBS} ; 30 \mathrm{~min}, 37^{\circ} \mathrm{C}\right)$, washed gently, nuclei labeled with DAPI, and slices mounted. Staining specificity was confirmed by ablation of the signal by preincubating sections with $500 \mathrm{IU} / \mathrm{ml}$ PEG-superoxide dismutase (Sigma).

For histological quantification (DNA damage, differentiation), at least 30 representative transverse heart sections from ventricles and atria were used.

For ICC quantification, at least 100 cells from at least three mice were used. Positive cells were counted manually using ImageJ software ((Fiji) v2.0.0 (2015; NIH)). BMI1and H2Aub-positive surface areas were quantified by acquiring random images of nuclei $(630 \times)$ and calculating the number of stained surfaces per total surface in ImageJ.

Images were captured with a Zeiss LSM 700 or Leica TCS SP5. Processing, including assignment of pseudocolors and changes in brightness, was applied uniformly to the entire image to equalize the appearance of multiple panels in a single figure.

\section{Isolation of adult mouse cardiomyocytes, non- myocyte cells, cell culture}

Non-myocyte cells and cardiomyocytes were obtained by the Langendorff method using retrograde perfusion through the aorta [19]. Sca1 ${ }^{+} \mathrm{CD} 45^{-}$cells were cultured in Iscove's modified Dulbecco's medium (Invitrogen) containing 10\% fetal bovine serum (ESCell FBS, Gibco), $100 \mathrm{IU} / \mathrm{ml}$ penicillin, $100 \mathrm{mg} / \mathrm{ml}$ streptomycin, and $2 \mathrm{mM}$ L-glutamine (all from Invitrogen), $10^{3}$ units ESGRO Supplement (Millipore), $10 \mathrm{ng} / \mathrm{ml}$ epidermal growth factor (Sigma) and $20 \mathrm{ng} /$ $\mathrm{ml}$ fibroblast growth factor (Peprotech) $\left(37^{\circ} \mathrm{C}, 3 \% \mathrm{O}_{2}, 5 \%\right.$ $\left.\mathrm{CO}_{2}\right)$.

\section{Flow cytometry}

For flow cytometry analysis, hearts were digested by the Langendorff method and cell- or cardiomyocyte-enriched fractions analyzed. Total ROS was detected using CellROX (ThermoFisher), following the manufacturer's protocols.
Cell sorters used were Beckman Coulter Moflow XDP and BD FacsAria II Special Order System, and cell cytometers were Beckman Coulter GALLIOS Analyzer and BD FACSCanto II. FlowJo vX1 was used for data analysis.

\section{Western blotting and HPLC}

For Western blotting, cells and tissues were lysed (45 min, $4^{\circ} \mathrm{C}$ ) in radioimmunoprecipitation assay buffer (RIPA; Sigma-Aldrich), with addition of cOmplete, EDTA-free Protease Inhibitor Cocktail (Roche). Proteins were quantitated using the Infinite m200 (Tecan). Lysates were size fractionated by sodium dodecyl sulfate (SDS)-polyacrylamide gel electrophoresis, transferred to Hybond ECL nitrocellulose membranes (GE Healthcare), probed with indicated antibodies (Supplementary Table S3), and analyzed by enhanced chemiluminescence (GE Healthcare).

Protein carbonyls and thiobarbituric acid-reactive substances were determined in perfused heart homogenates as described [59, 60].

\section{ChIP assays and sequencing}

For ChIP analysis, we used a $\mathrm{Sca}^{+} \mathrm{CD} 45^{-}$-enriched cardiac population. After Langendorff heart digestion, we depleted the hematopoietic lineage $\left(\mathrm{CD} 45^{+}\right)$by immunomagnetic separation (AutoMACS Pro Separator); the SCA$1^{+}$fraction was purified by magnetic cell sorting using a lineage cell depletion kit and Sca1 microbeads (all from Miltenyi Biotec). Homeostasis and damaged Sca $1^{+} \mathrm{CD} 45^{-}$ cells were isolated and immunoprecipitated synchronically to avoid procedural differences.

After isolating the $\mathrm{Sca} 1^{+} \mathrm{CD} 45^{-}$cardiac population, formaldehyde was added directly to the cell suspension (final concentration 1\%) and cell were incubated on a shaking platform (10 min, RT). Crosslinking was terminated by adding glycine ( $0.125 \mathrm{M} ; 5 \mathrm{~min})$. Crosslinked cells were washed twice with cold PBS and lysed in 1\% SDS, 50 $\mathrm{mM}$ Tris- $\mathrm{HCl}(\mathrm{pH} \mathrm{8.0)}$, and $10 \mathrm{mM}$ EDTA, with protease inhibitors $\left(15 \mathrm{~min}, 4^{\circ} \mathrm{C}\right)$. Lysates were sonicated to obtain chromatin fragments $<1 \mathrm{~kb}$, then centrifuged (15 min, RT), diluted 1:10 with $1.1 \%$ Triton-X 100, 2 mM EDTA, 150 $\mathrm{mM} \mathrm{NaCl}$, and $20 \mathrm{mM}$ Tris- $\mathrm{HCl}$ ( $\mathrm{pH} 8.0$ ) containing protease inhibitors, precleared with $50 \%$ salmon sperm DNA and protein A agarose slurry (Upstate). Antibodies were added $\left(\mathrm{O} / \mathrm{N}, 4^{\circ} \mathrm{C}\right.$ ) (for antibodies used, see Supplementary Table S3). We then added salmon sperm DNA and protein A agarose beads $(60 \mu \mathrm{l})$ and incubated $\left(1 \mathrm{~h}, 4{ }^{\circ} \mathrm{C}\right)$. Samples were centrifuged and immunoprecipitated pellets washed with $0.1 \%$ SDS, $1 \%$ Triton-X 100, 2 mM EDTA, $20 \mathrm{mM}$ Tris- $\mathrm{HCl}(\mathrm{pH} 8.0), 150 \mathrm{mM} \mathrm{NaCl}$ (once); $0.1 \%$ SDS, $1 \%$ Triton-X 100, 2 mM EDTA, 20 mM Tris-HCl (pH 8.0), 500 $\mathrm{mM} \mathrm{NaCl}$ (once); $0.25 \mathrm{M} \mathrm{LiCl,} 1 \%$ Nonidet P-40, $1 \%$ 
sodium deoxycholate, $1 \mathrm{mM}$ EDTA, $10 \mathrm{mM}$ Tris-HCl (pH 8.0) (once); and $10 \mathrm{mM}$ Tris- $\mathrm{HCl}$ (pH 8.0), $1 \mathrm{mM}$ EDTA (twice). Chromatin was eluted from beads twice by incubation with $250 \mu \mathrm{l} 1 \% \mathrm{SDS}, 0.1 \mathrm{M} \mathrm{NaHCO}_{3}$, with rotation (15 min, RT). Crosslinking was reversed by adding $20 \mu \mathrm{l} 5$ $\mathrm{M} \mathrm{NaCl}\left(4 \mathrm{~h}, 65^{\circ} \mathrm{C}\right)$. Samples were supplemented with 20 $\mu \mathrm{l} 1 \mathrm{M}$ Tris- $\mathrm{HCl}$ (pH 6.5), $10 \mu \mathrm{l} 0.5 \mathrm{M}$ EDTA, $20 \mu \mathrm{g}$ RNase $\mathrm{A}$ and $40 \mu \mathrm{g}$ proteinase $\mathrm{K}$, and incubated $\left(1 \mathrm{~h}, 45^{\circ} \mathrm{C}\right)$, followed by DNA isolation using a kit (MO BIO).

Libraries were prepared using the NEBNext Ultra DNA Library Prep for Illumina kit (E7370; New England Biolabs). Briefly, from 1 to $5 \mathrm{ng}$ of input and ChIP-enriched DNA were subjected to end repair and addition of "A" bases to $3^{\prime}$ ends, ligation of adapters and USER excision. All purification steps were performed using AgenCourt AMPure XP beads (A63881, Qiagen). Libraries were amplified by PCR using NEBNext Multiplex Oligos for Illumina (Index Primers Set 1; E7335 or Index Primers Set 2; E7500). Final libraries were analyzed using Agilent High Sensitivity chip to estimate, quantity and confirm size distribution, and then quantified by qPCR using the KAPA Library Quantification Kit (KK4835, KapaBiosystems) prior to amplification with Illumina cBot. Libraries were loaded at a $1.42 \mathrm{pM}$ concentration onto the flow cell and were sequenced $1 \times 50$ on Illumina HiSeq 2500 .

Raw reads in FASTQ format were quality controlled with FASTQC. For each sample, ChIP DNA sequence reads were mapped to the mouse genome (Ensembl version GRCm38.85) using Bowtie2 software. For ChIP-Seq analysis, we used the HOMER suite. For further HOMER analysis, aligned data were first transformed in an independent platform using the makeTagDirectory function to allow mapping quality with default settings. The HOMER findPeaks-style factor function was then used to identify genome regions in which more sequencing reads were present than would be expected by chance. The FindPeaks function was applied to each sample individually and the two INPUTS together as control. The HOMER getdifferential function was used to find peaks differentially enriched between experiments. To add information about the replicate in which the peak was detected, mergePeaks function was used to combine all results. To annotate peaks, we used annotatePeaks.pl. Additional gene symbols and descriptions were obtained from BioMart. The bedtools Getfasta function was used to extract peak sequences. All information was visualized using the Integrative Genomics Viewer (IGV).

\section{RT-qPCR analysis}

RNA was purified using the Cells-to-CT kit (Ambion, Thermo). Complementary DNA (cDNA) was obtained by reverse transcription with the High Capacity cDNA Reverse
Transcription Kit (Applied Biosystems). cDNAs were analyzed by real-time PCR using the Power SYBR Green PCR Master Mix (Applied Biosystems). Amplification, detection, and data analysis were carried out with an ABI PRISM 7900HT Sequence Detection System and normalized to GUSB and GAPDH expression. Changes in mRNA expression are noted as $x$-fold change relative to the control. For ChIP-qPCR, we used an unrelated genomic locus $22 \mathrm{~kb}$ upstream of the Pitx2 gene transcription start site as a negative control (NC). Amplicons are illustrated in Fig. 5a and qPCR primers are listed in Supplementary Table 3. ChIP signals were represented as a fold change of input chromatin.

\section{Statistical analysis}

Statistical analyses were performed with $\mathrm{R}$ version 3.2.4. Statistical comparisons between data sets were made with analysis of normality and variance, followed by an unpaired Student's $t$-test for comparing differences between two groups and analysis of variance (ANOVA) test for over two groups, as detailed in the figures. A value of $p<0.05$ was considered significant. All replicates considered are biological replicates.

\section{Accession numbers}

The GEO accession number for ChIP-seq data reported in this article is GSE92700 (Supplementary Table 3).

Acknowledgements We thank S. Gutiérrez for assistance with confocal microscopy, J.C. Oliveros and M. Franch for bioinformatics, M.C. Moreno and S. Escudero for the sorting strategy, M Serrano for G6PD ${ }^{\mathrm{tg}}$ mouse line, N. Fonseca-Balvis for her valuable input, and C. Mark for editorial support. D.H., M.T., and F.M.C. were predoctoral fellows from the Spanish Ministry of Economy and Competitiveness. This study was supported by grants to A.B. from the Spanish Ministry of Science and Innovation (PLE2009-0147), the Ministry of Economy and Competitiveness (SAF2015-70882-R), Comunidad Autónoma de Madrid (S2011/ BMD-2420), Instituto de Salud Carlos III (RETICS-RD12/0018) and the European Commission (HEALTH-2009_242038), and by a grant from the Generalitat Valenciana (PROMOTEO/2016/006) to E.R. The CNBCSIC and CNIC are supported by the Spanish Ministry of Economy and Competitiveness.

Author contributions D.H. conceived, performed, and designed experiments, developed the project, contributed ideas, and wrote the manuscript. M.T., S.C., and F.M.C. performed and designed experiments. R.M.C., E.F., and E.R. performed experiments. A.B. conceived and developed the project, designed experiments, interpreted results, and wrote the manuscript. All authors read and approved the final manuscript.

\section{Compliance with ethical standards}

Competing interests The authors declare that they have no competing financial interests. 


\section{References}

1. Uygur A, Lee RT. Mechanisms of cardiac regeneration. Dev Cell 2016;36:362-374.

2. Noseda M, Abreu-Paiva M, Schneider MD. The Quest for the Adult Cardiac Stem Cell. Circ J 2015;79:1422-1430.

3. Valente M, Nascimento DS, Cumano A, Pinto-do-Ó P. Sca-1+ cardiac progenitor cells and heart-making: a critical synopsis. Stem Cells Dev 2014;23:2263-2273.

4. Noseda M, Harada M, McSweeney S, Leja T, Belian E, Stuckey $\mathrm{DJ}$, et al PDGFR $\alpha$ demarcates the cardiogenic clonogenic Sca1 $(+)$ stem/progenitor cell in adult murine myocardium. Nat Commun 2015;6:6930.

5. Pfister O, Mouquet F, Jain M, Summer R, Helmes M, Fine A, et al CD31- but Not CD31+cardiac side population cells exhibit functional cardiomyogenic differentiation. Circ Res 2005;97:52-61.

6. Ushio-Fukai M, Rehman J. Redox and metabolic regulation of stem/progenitor cells and their niche. Antioxid Redox Signal 2014;21:1587-1590.

7. Kimura W, Xiao F, Canseco DC, Muralidhar S, Thet S, Zhang $\mathrm{HM}$, et al Hypoxia fate mapping identifies cycling cardiomyocytes in the adult heart. Nature 2015;523:226-230.

8. Kocabas F, Mahmoud AI, Sosic D, Porrello ER, Chen R, Garcia $\mathrm{JA}$, et al The hypoxic epicardial and subepicardial microenvironment. J Cardiovasc Transl Res 2012;5:654-665.

9. Nombela-Arrieta C, Pivarnik G, Winkel B, Canty KJ, Harley B, Mahoney JE, et al Quantitative imaging of haematopoietic stem and progenitor cell localization and hypoxic status in the bone marrow microenvironment. Nat Cell Biol 2013;15:533-543.

10. Shen Q, Goderie SK, Jin L, Karanth N, Sun Y, Abramova N, et al Endothelial cells stimulate self-renewal and expand neurogenesis of neural stem cells. Science 2004;304:1338-1340.

11. Zhang CC, Sadek HA. Hypoxia and metabolic properties of hematopoietic stem cells. Antioxid Redox Signal 2014;20:1891-1901.

12. Inomata $\mathrm{K}$, Aoto $\mathrm{T}$, Binh $\mathrm{NT}$, Okamoto $\mathrm{N}$, Tanimura $\mathrm{S}$, Wakayama $\mathrm{T}$, et al Genotoxic stress abrogates renewal of melanocyte stem cells by triggering their differentiation. Cell 2009; 137:1088-1099.

13. Schieber M, Chandel NS. ROS function in redox signaling and oxidative stress. Curr Biol 2014;24:R453-462.

14. Cao Y, Fang Y, Cai J, Li X, Xu F, Yuan N, et al ROS functions as an upstream trigger for autophagy to drive hematopoietic stem cell differentiation. Hematology 2016;21:613-618.

15. Puente BN, Kimura W, Muralidhar SA, Moon J, Amatruda JF, Phelps KL, et al The oxygen-rich postnatal environment induces cardiomyocyte cell-cycle arrest through DNA damage response. Cell 2014;157:565-579.

16. Sangiorgi E, Capecchi MR. Bmi1 is expressed in vivo in intestinal stem cells. Nat Genet 2008;40:915-920.

17. Biehs B, Hu JK, Strauli NB, Sangiorgi E, Jung H, Heber RP, et al BMI1 represses Ink4a/Arf and Hox genes to regulate stem cells in the rodent incisor. Nat Cell Biol 2013;15:846-852.

18. Komai Y, Tanaka T, Tokuyama Y, Yanai H, Ohe S, Omachi T, et al Bmil expression in long-term germ stem cells. Sci Rep 2014;4:6175.

19. Valiente-Alandi I, Albo-Castellanos C, Herrero D, Arza E, GarciaGomez M, Segovia JC, et al Cardiac Bmil (+) cells contribute to myocardial renewal in the murine adult heart. Stem Cell Res Ther 2015;6:205.

20. Wang H, Wang L, Erdjument-Bromage H, Vidal M, Tempst P, Jones RS, et al Role of histone H2A ubiquitination in Polycomb silencing. Nature 2004;431:873-878.
21. Zhou Y, Wang L, Vaseghi HR, Liu Z, Lu R, Alimohamadi S, et al Bmil Is a Key Epigenetic Barrier to Direct Cardiac Reprogramming. Cell Stem Cell 2016;18:382-395.

22. Jacobs JJ, Kieboom K, Marino S, DePinho RA, van Lohuizen M. The oncogene and Polycomb-group gene bmi-1 regulates cell proliferation and senescence through the ink $4 \mathrm{a}$ locus. Nature 1999;397:164-168.

23. Abdouh M, Hanna R, El Hajjar J, Flamier A, Bernier G. The Polycomb Repressive Complex 1 Protein BMI1 Is Required for Constitutive Heterochromatin Formation and Silencing in Mammalian Somatic Cells. J Biol Chem 2016;291:182-197.

24. Ginjala V, Nacerddine K, Kulkarni A, Oza J, Hill SJ, Yao M, et al BMI1 is recruited to DNA breaks and contributes to DNA damage-induced $\mathrm{H} 2 \mathrm{~A}$ ubiquitination and repair. Mol Cell Biol 2011;31:1972-1982.

25. Wei F, Ojo D, Lin X, Wong N, He L, Yan J, et al BMI1 attenuates etoposide-induced G2/M checkpoints via reducing ATM activation. Oncogene 2014;34:3063-3075.

26. Liu J, Cao L, Chen J, Song S, Lee IH, Quijano C, et al Bmi1 regulates mitochondrial function and the DNA damage response pathway. Nature 2009;459:387-392.

27. Banerjee Mustafi S, Aznar N, Dwivedi SK, Chakraborty PK, Basak R, Mukherjee P, et al Mitochondrial BMI1 maintains bioenergetic homeostasis in cells. FASEB J 2016;30: 4042-4055.

28. Wang K, Zhang T, Dong Q, Nice EC, Huang C, Wei Y. Redox homeostasis: the linchpin in stem cell self-renewal and differentiation. Cell Death Dis 2013;4:e537.

29. Hosen N, Yamane T, Muijtjens M, Pham K, Clarke MF, Weissman IL. Bmi-1-green fluorescent protein-knock-in mice reveal the dynamic regulation of bmi-1 expression in normal and leukemic hematopoietic cells. Stem Cells 2007;25:1635-1644.

30. Di Foggia V, Zhang X, Licastro D, Gerli MF, Phadke R, Muntoni $\mathrm{F}$, et al Bmil enhances skeletal muscle regeneration through MT1-mediated oxidative stress protection in a mouse model of dystrophinopathy. J Exp Med 2014;211:2617-2633.

31. Chen Y, Li L, Ni W, Zhang Y, Sun S, Miao D, et al Bmil regulates auditory hair cell survival by maintaining redox balance. Cell Death Dis 2015;6:e1605.

32. Cruz FM, Tomé M, Bernal JA, Bernad A. miR-300 mediates Bmil function and regulates differentiation in primitive cardiac progenitors. Cell Death Dis 2015;6:e1953.

33. Malliaras K, Ibrahim A, Tseliou E, Liu W, Sun B, Middleton RC, et al Stimulation of endogenous cardioblasts by exogenous cell therapy after myocardial infarction. EMBO Mol Med 2014;6:760-777.

34. Maher TJ, Ren Y, Li Q, Braunlin E, Garry MG, Sorrentino BP, et al ATP-binding cassette transporter Abcg2 lineage contributes to the cardiac vasculature after oxidative stress. Am J Physiol Heart Circ Physiol 2014;306:H1610-1618.

35. Lee YJ, Park SJ, Ciccone SL, Kim CR, Lee SH. An in vivo analysis of MMC-induced DNA damage and its repair. Carcinogenesis 2006;27:446-453.

36. Liu Q, Yang R, Huang X, Zhang H, He L, Zhang L, et al Genetic lineage tracing identifies in situ Kit-expressing cardiomyocytes. Cell Res 2016;26:119-130.

37. Ohtsubo M, Yasunaga S, Ohno Y, Tsumura M, Okada S, Ishikawa N, et al Polycomb-group complex 1 acts as an E3 ubiquitin ligase for Geminin to sustain hematopoietic stem cell activity. Proc Natl Acad Sci USA 2008;105:10396-10401.

38. Bednar F, Schofield HK, Collins MA, Yan W, Zhang Y, Shyam $\mathrm{N}$, et al Bmil is required for the initiation of pancreatic cancer through an Ink4a-independent mechanism. Carcinogenesis 2015;36:730-738. 
39. Ismail IH, Andrin C, McDonald D, Hendzel MJ. BMI1-mediated histone ubiquitylation promotes DNA double-strand break repair. J Cell Biol 2010;191:45-60.

40. Chagraoui J, Hébert J, Girard S, Sauvageau G. An anticlastogenic function for the Polycomb Group gene Bmil. Proc Natl Acad Sci U S A 2011;108:5284-5289.

41. Pouyet L, Carrier A. Mutant mouse models of oxidative stress. Transgenic Res 2010;19:155-164.

42. Gu M, Shen L, Bai L, Gao J, Marshall C, Wu T, et al Heterozygous knockout of the Bmi-1 gene causes an early onset of phenotypes associated with brain aging. Age (Dordr) 2014;36:129-139.

43. Nóbrega-Pereira S, Fernandez-Marcos PJ, Brioche T, GomezCabrera MC, Salvador-Pascual A, Flores JM, et al G6PD protects from oxidative damage and improves healthspan in mice. Nat Commun 2016;7:10894.

44. Gargiulo G, Cesaroni M, Serresi M, de Vries N, Hulsman D, Bruggeman SW, et al In vivo RNAi screen for BMI1 targets identifies TGF- $\beta$ /BMP-ER stress pathways as key regulators of neural- and malignant glioma-stem cell homeostasis. Cancer Cell 2013;23:660-676.

45. Kimura W, Muralidhar S, Canseco DC, Puente B, Zhang CC, Xiao F, et al Redox signaling in cardiac renewal. Antioxid Redox Signal 2014;21:1660-1673.

46. Drenckhahn JD, Schwarz QP, Gray S, Laskowski A, Kiriazis H, Ming $\mathrm{Z}$, et al Compensatory growth of healthy cardiac cells in the presence of diseased cells restores tissue homeostasis during heart development. Dev Cell 2008;15:521-533.

47. Crespo FL, Sobrado VR, Gomez L, Cervera AM, McCreath KJ. Mitochondrial reactive oxygen species mediate cardiomyocyte formation from embryonic stem cells in high glucose. Stem Cells 2010;28:1132-1142.

48. Buggisch M, Ateghang B, Ruhe C, Strobel C, Lange S, Wartenberg M, et al Stimulation of ES-cell-derived cardiomyogenesis and neonatal cardiac cell proliferation by reactive oxygen species and NADPH oxidase. J Cell Sci 2007;120(Pt 5):885-894.

49. Hämäläinen RH, Ahlqvist KJ, Ellonen P, Lepistö M, Logan A, Otonkoski T, et al mtDNA Mutagenesis Disrupts Pluripotent Stem Cell Function by Altering Redox Signaling. Cell Rep 2015;11:1614-1624.
50. Falluel-Morel A, Lin L, Sokolowski K, McCandlish E, Buckley B, DiCicco-Bloom E. N-acetyl cysteine treatment reduces mercury-induced neurotoxicity in the developing rat hippocampus. J Neurosci Res 2012;90:743-750.

51. García-Prat L, Martínez-Vicente M, Perdiguero E, Ortet L, Rodríguez-Ubreva J, Rebollo E, et al Autophagy maintains stemness by preventing senescence. Nature 2016;529:37-42.

52. Sato A, Okada M, Shibuya K, Watanabe E, Seino S, Narita Y, et al Pivotal role for ROS activation of p38 MAPK in the control of differentiation and tumor-initiating capacity of glioma-initiating cells. Stem Cell Res 2014;12:119-131.

53. Yamaguchi M, Kashiwakura I. Role of reactive oxygen species in the radiation response of human hematopoietic stem/progenitor cells. PLoS One 2013;8:e70503.

54. Le HQ, Ghatak S, Yeung CY, Tellkamp F, Günschmann C, Dieterich $\mathrm{C}$, et al Mechanical regulation of transcription controls Polycomb-mediated gene silencing during lineage commitment. Nat Cell Biol 2016;18:864-875.

55. Kloet SL, Makowski MM, Baymaz HI, van Voorthuijsen L, Karemaker ID, Santanach A, et al The dynamic interactome and genomic targets of Polycomb complexes during stem-cell differentiation. Nat Struct Mol Biol 2016;23:682-690.

56. Molofsky AV, Pardal R, Iwashita T, Park IK, Clarke MF, Morrison SJ. Bmi-1 dependence distinguishes neural stem cell selfrenewal from progenitor proliferation. Nature 2003;425: 962-967.

57. Landais S, D'Alterio C, Jones DL. Persistent replicative stress alters polycomb phenotypes and tissue homeostasis in Drosophila melanogaster. Cell Rep 2014;7:859-870.

58. Gu BW, Fan JM, Bessler M, Mason PJ. Accelerated hematopoietic stem cell aging in a mouse model of dyskeratosis congenita responds to antioxidant treatment. Aging Cell 2011;10:338-348.

59. Lotito SB, Fraga CG. Catechins delay lipid oxidation and alphatocopherol and beta-carotene depletion following ascorbate depletion in human plasma. Proc Soc Exp Biol Med 2000;225:32-38.

60. Levine RL, Williams JA, Stadtman ER, Shacter E, Carbonyl assays for determination of oxidatively modified proteins. Methods Enzymol. 1994;233:346-357 